\title{
Factors in the practice environment of nurses working in inpatient mental health: A partial least squares path modeling approach.
}

\begin{abstract}
Background: Developing a therapeutic relationship with consumers is considered the central aspect of nursing work in mental health. The importance of this relationship stems from its association with enhanced patient care and improved patient outcomes. Factors within the practice environment may influence the nurse's ability to engage effectively in this relationship.

Objective: This study explored a model that added characteristics of the individual and practice environment to a central framework incorporating therapeutic commitment: a nurse's ability and willingness to engage in a therapeutic relationship.
\end{abstract}

Setting and Participants: Data were collected on six mental health nursing units in five public general acute hospitals in New South Wales, Australia for 14 days per unit, between 2005 and 2006. All nurses on participating wards were invited to partake in the study. Seventy-six (51\%) responses were analyzed.

Method: The data were collected using a Nurse Survey inclusive of the Practice Environment Scale of the Nursing Work Index (NWI-PES), and the Mental Health Problems Perception Questionnaire (MHPPQ). A Unit Profile form was used concurrently to collect staffing, skill mix and patient turnover data. Partial least squares path modeling (PLS-PM) was chosen as the analytical method to test the model and identify the most influential factors.

Results: Experienced nurses who perceived themselves to be competent and supported were more likely to express a willingness to engage therapeutically with patients. Environmental factors associated with these perceptions included foundations of quality nursing care, opportunities to participate in hospital affairs and clinical supervision. Not all elements in the proposed model were supported.

Conclusion: Positive hospital practice environments can improve the capacity of nurses working in mental health to engage therapeutically with patients. Specific approaches may include access to preceptorship, continued education and career development opportunities, together with clinical 
supervision, improved continuity of care, and the involvement of mental health nurses in the governance of the hospital.

KEYWORDS: Hospital Nursing Staff, Mental Health Nursing, Practice Environment, Therapeutic Relationships, Partial Least Squares Path Modeling.

\section{What is already known about the topic?}

- Positive practice environments have been linked to nurse job satisfaction and retention, and a range of positive patient outcomes.

- Aspects of the practice environment can impede or enhance the development of therapeutic relationships, which has several consequences for nurse and patient outcomes in medical and surgical nursing settings.

- There is relatively little published quantitative research that examines environmental factors that influence nurses' capacity to effectively engage in therapeutic relationships, especially within a mental health context.

\section{What this paper adds:}

- A number of characteristics of the practice environment, similar to those identified in medical and surgical settings, were found to influence nurses' ability and willingness to engage in therapeutic relationships.

- Major environmental factors included the foundations for quality care and nurses' participation in hospital affairs. The nurse's experience in mental health was also significant.

- These and other characteristics of the environment and the individual require further exploration. 


\section{Background}

The therapeutic relationship is a central facet of nursing (Peplau, 1992, Peplau, 1997, Peplau, 1989), and is a particular focus in caring for individuals experiencing mental illness (Barker, 1990, Barker et al., 1999). It is defined by Peplau (1997) as a specific interpersonal relationship in which recurring difficulties of life will arise, and, in order to overcome these difficulties, it requires both nurse and patient ${ }^{1}$ to work cohesively towards a solution. Effective therapeutic relationships have been linked to positive outcomes such as improved adherence to prescribed medications, increased involvement in care and increased quality of life (Dziopa and Ahern, 2009, Forchuk and Reynolds, 2001, Shattell et al., 2007). These outcomes may be achieved through the development of the patient's understanding of themselves and their health, which are in turn influenced by nurses' capacity to relate in a therapeutic manner (Hummelvoll, 1996, Peplau, 1997, Stockmann, 2005).

A large number of studies have identified relationships between characteristics of the practice environment and outcomes for nurses, such as job satisfaction, and for patients, such as falls and medication errors (e.g. Aiken et al., 2003, Duffield et al., In Press, Van den Heede et al., 2007). While the majority of these studies have focused on medical and surgical nursing, some have examined mental health settings and identified potential influences on nurse burnout and patient aggression (Hanrahan, 2007, Hanrahan et al., 2010). In addition, some studies have suggested a link between the mental health nursing practice environment and the therapeutic relationship (Bowers et al., 2010, Brennan et al., 2006).

The mental health nurse's ability to engage in therapeutic relationships is fundamental to their role, and factors that may influence this capacity should therefore be explored. Elements of the practice environment were drawn from mental health nursing and other research and added to a model that describes factors linked to the nurse's ability and willingness to relate therapeutically. This paper describes the exploration of that model in order to identify whether the specified environmental and individual factors relate to the capacity to engage, and to identify key factors and relationships.

\section{A Model of Commitment}

The model tested is presented in Figure 1. It is base on a framework developed by Lauder and colleagues (Angus et al., 2001, Angus et al., 2001, Lauder et al., 2000). They expanded on previous research that used the term 'therapeutic commitment' to describe a health professional's ability and

\footnotetext{
${ }^{1}$ The authors acknowledge that the terms 'service user', 'client' or 'consumer' are commonly used when referring to people engaged in treatment for mental health problems. The focus of this paper is on nursing people admitted to hospital, defined as patients (Australian Institute of Health and Welfare [AlHW], 2010a; AlHW, 2010b). This term has been used throughout the document in order to avoid confusion.
} 
willingness to engage therapeutically with patients (Cartwright, 1981, Cartwright, 1980, Shaw et al., 1978). Underlying this work is Rogers' (1957) foundational work that declared health professionals need to be authentic, congruent, respectful and trusting; to display unconditional positive regard. This view is consistent with mental health nursing as a patient-centered activity with an emphasis on trust, empathy and respect (Altschul, 1972, Barker, 1990, Peplau, 1992).

Figure 1 Initial Model

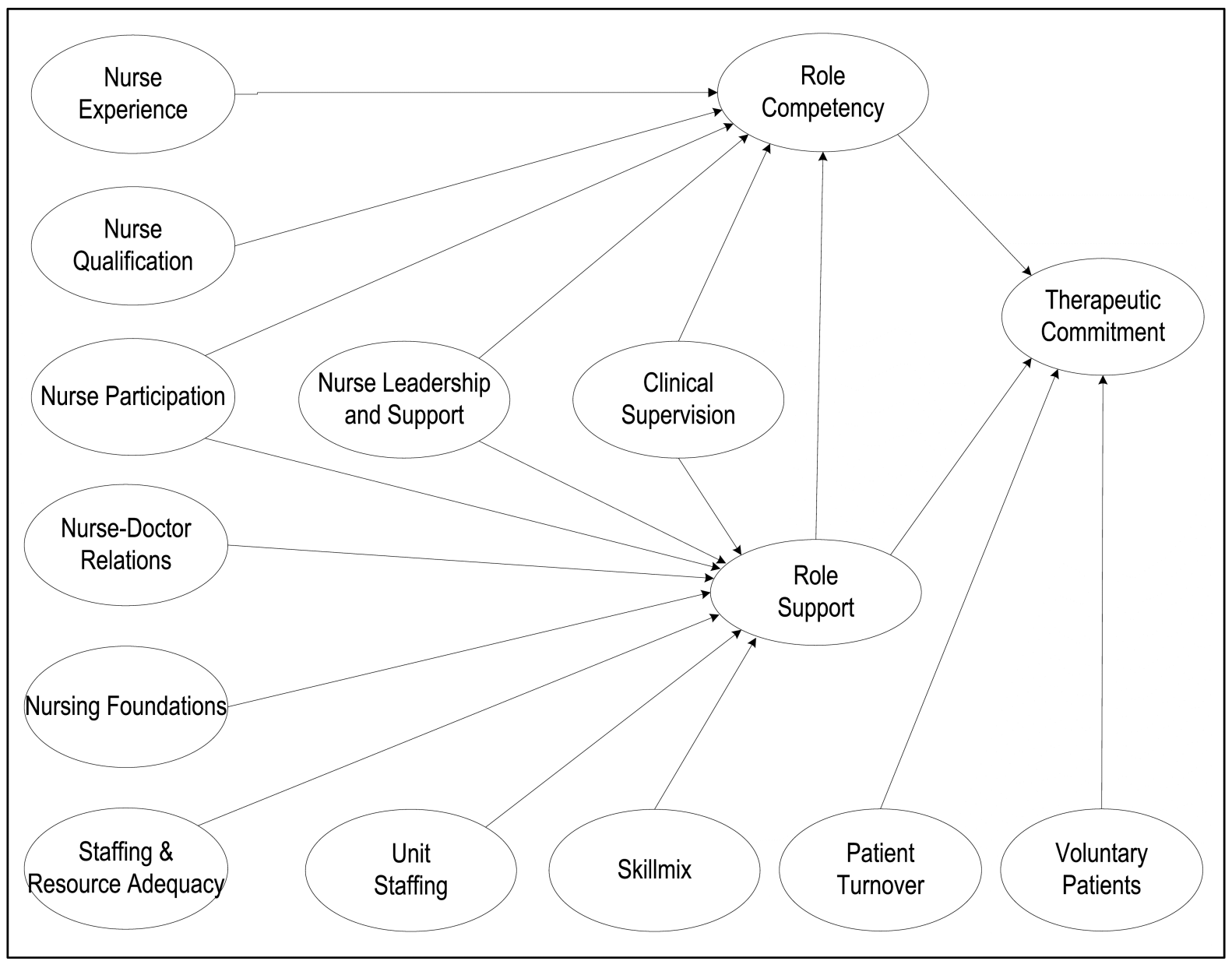

Lauder et al. (2000) linked the nurse's perception of support and competency to their ability and willingness to engage therapeutically. Three core elements were identified: therapeutic commitment, role support and role competency. Therapeutic commitment was held to be influenced by the organizational support provided to nurses, both directly and through the influence of support on role competency: their perceived legitimacy in working with mental health patients and their belief that they have adequate skills and knowledge (Lauder et al., 2002). A nurse with high therapeutic commitment was said to establish an interpersonal climate that facilitated engagement 
and trust, potentially leading to increased empathy and more effective therapeutic work (Angus et al., 2001, Lauder et al., 2002, Reynolds and Scott, 2000).

Research using this core framework (Albery et al., 2003) found that contextual factors such as time and policy constraints were linked to levels of role competency and therapeutic commitment. Consequently, for this study, a number of factors were drawn from the literature to build a model centered on the three core elements (Figure 1). The aims of this study were to (1) test a model of hypothesized relationships between aspects of the practice environment and the therapeutic commitment of nurses working in mental health, and to (2) identify those characteristics of the practice environment that impact most significantly on therapeutic commitment.

\section{Additional Factors}

The additional factors added to the core elements were identified as potential influences on the nurse's willingness and ability to engage therapeutically. These factors were considered influential through the support they provide to the nurse in their role, through their effect on the nurse's belief that they are legitimately in the role, through their skills and knowledge, or directly on their therapeutic commitment.

Nurse Qualifications. The educational level of health professionals is often cited as an important influence on their capacity to engage successfully with patients (Horvath, 2005, Hughes et al., 2008). In medical-surgical nursing, a higher proportion of Bachelor-prepared nurses has been associated with reduced mortality (Aiken et al., 2003) and lower rates of violence (Roche et al., 2010). In Australia, the basic qualification is a Bachelor degree for a Registered Nurse (RN) and a certificate for Enrolled Nurse (EN; similar to LVN/LPN in the United States). These are general qualifications and specific mental health nursing education occurs in the postgraduate arena. In this study, the level of mental health qualification ('qualifications') was considered a potential influence on skills, knowledge and legitimacy, so was linked to role competency.

Nurse Experience. Experience has been identified as a significant factor in the capacity of health professionals to relate therapeutically with patients (Horvath, 2005). Studies using the three core elements on which this model is based have identified associations between the individual's clinical experience and role competency (Airey and Marriott, 2003, Albery et al., 2003). In addition, supported experience and feedback has been found to assist the interpretation of events in a way that enhances learning and skill development (Bandura, 2001, Brown et al., 2005). Therefore, experience was linked to role competency.

Clinical Supervision. Related to experience is its interpretation. In mental health and other settings, clinical supervision has been found to be a major supportive factor (Butterworth et al., 
1999, Hyrkas, 2005). However, with the inclusion of educational and governance aspects in the commonly applied Proctor (1986) model (White and Roche, 2006), it can also be linked to role competency. Although research examining clinical supervision in Australia has found little consistency within or across organizations in regard to model, type (group or individual) or frequency (White and Roche, 2006), in this study clinical supervision is linked to both role support and role competency.

Leadership \& Management Support. Effective nursing leadership at the nursing unit (ward) and hospital level has been linked to positive outcomes for nurses and patients in general nursing settings (Aiken et al., 2008, Laschinger and Leiter, 2006, Leiter and Laschinger, 2006). Nursing leadership has been associated with Australian nurses' job satisfaction and their intention to leave their current job (Duffield et al., 2009). In Canada, Laschinger, Finegan and Wilk (2009) found an association between nursing leadership, workplace conditions and nurses' commitment to the organization across 217 hospital wards.

Leadership can enable clinical nurse autonomy through clear management structures and nursing representation (Schmalenberg and Kramer, 2008). For example, New Zealand nurses suggested that effective leadership provided clarity and direction at the ward and organizational level (Hansen et al., 2007). Similarly, Hanrahan et al. (2010) found an association between effective leadership and decreased nurse burnout amongst mental health nurses. In the present study, leadership is considered to influence both support and role competency.

Nurse Participation in Hospital Affairs. Together with effective leadership, greater participation in hospital affairs has been linked to improved quality of care and greater perceived personal accomplishment at work (Van Bogaert et al., 2009). This participation may provide career development opportunities and could be linked to both role support and role competency. In Australia, the mental health practice environment has experienced significant change over several decades through deinstitutionalization and mainstreaming, where services have moved from specific mental health organizations to acute care general hospitals (AIHW, 2004, Department of Health and Ageing, 2009). One consequence may be that nurses in mental health find it difficult to participate in the general hospital hierarchy (Mental Health Council of Australia, 2005).

Nursing Foundations for Quality of Care. The building blocks for quality nursing care (foundations) provide support for nurses (Lake, 2002). They include support to undertake continued education, the availability of preceptors for new staff, the expectation of a high standard of care, and a nursing model of service provision. These foundations, in combination with other environmental characteristics, have been associated with patient mortality, failure to rescue, job 
satisfaction, burnout and quality of care (Aiken et al., 2008, Armstrong et al., 2009). In Finland, organizational expectation of high standards of nursing care was linked to decreased nurse stress, increased job satisfaction, fewer adverse events for patients and nurses, and improved patient satisfaction (Tervo-Heikkinen et al., 2008).

In Australian mental health services, these building blocks may not be present. For example, hospital support for continued education has been questioned (Australian Health Workforce Advisory Committee, 2003) and the uptake of state-funded scholarships for postgraduate education has been low (NSW Labour Economics Office, 2008, Pagnini, 2005). In this study the presence of these foundations were believed to influence role support.

Collegial Nurse-Doctor Relationships. International nursing research has identified effective working relationships between nurses and doctors as having a significant influence on outcomes (Aiken et al., 2008, Duffield et al., In Press, Gunnarsdóttir et al., 2007). In mental health nursing, Hanrahan and colleagues identified links between nurse-doctor relationships, burnout, quality of care and aggression (Hanrahan and Aiken, 2008, Hanrahan et al., 2010). More broadly looking at multidisciplinary teamwork, Alexander and colleagues (2005) found improved patient outcomes where teams worked together and Bowers et al. (2010) associated effective teamwork with good therapeutic engagement and fewer adverse events. Similarly, in Australia, cross-disciplinary approaches were found to be effective in reducing the seclusion and restraint of mental health patients (Gaskin et al., 2007). Taken together, this evidence suggests that nurse-doctor relationships have an important influence in role support.

Staffing. Staffing has been identified as having a significant influence on nurses' ability to complete their tasks and insufficient staffing levels have been linked to decreased job satisfaction (Aiken et al., 2001, Gunnarsdóttir et al., 2007), depersonalization and emotional exhaustion (Garrosa et al., 2008). In the mental health setting, low staffing has been linked to burnout (Hanrahan et al., 2010). It may decrease opportunity for interactions with patients, which has been linked to high readmission rates (Coleman and Paul, 2001) and more frequent use of seclusion (Donat, 2002). In this study, the concept of staffing, measured both as a ward variable and through individual nurse perceptions of the adequacy of staffing and other resources, is linked to role support.

Skill Mix. Skill mix is usually expressed as the proportion of RNs (Shullanberger, 2000, Van den Heede et al., 2007). Lower skill mix denotes a reduction in the proportion of RNs and an increase in the proportion of other categories of nurse. A systematic review of the literature in this area found that richer skill mix was associated with improved patient outcomes (Lankshear et al., 2005). It has been suggested that the expanded supervisory role of RNs in low skill mix wards includes more 
frequent interruptions and reduced capacity to support other RNs (Chang and Mark, 2009). In the model under study here, ward skill mix is linked to role support.

Patient Turnover. Similar to other nursing settings, in inpatient mental health it has been observed that nurses are often working with patients in the most acute stage of their illness (Cleary and Edwards, 1999, Coleman and Jenkins, 1998, NSW Mental Health Sentinel Events Review Committee, 2005). This movement of patients on and off the ward may limit opportunities for interaction and increase nurses' workload (Duffield et al., 2009). In particular, high patient turnover may adversely impact continuity of care, a factor that has been acknowledged as important in the development and maintenance of a trusting therapeutic relationship (Brennan et al., 2006, Wierdsma et al., 2009). In this study, patient turnover was linked directly to therapeutic commitment.

Voluntary Patients. In medical-surgical nursing settings, patient characteristics such as diagnosis, unit casemix, or patient acuity is often incorporated into the analysis to adjust for different levels of risk (e.g. Aiken et al., 2002, Duffield et al., In Press, Tourangeau et al., 2007). In mental health it has been suggested that patients severely affected by illness may be reluctant to engage with health professionals (Howgego et al., 2003), and factors such as diagnosis or functioning scores have been included in analyses.

For example, Forsyth (2007) found that nurses related more empathetically towards patients with a diagnosis of major depression compared to borderline personality disorder, and Alexander et al. (2005) noted that diagnosis and functioning scores were linked to improved daily living skills for long-term inpatients. In contrast, Bjørngaard, Ruud \& Friis (2007) found that patient characteristics were small contributors to patient satisfaction with the therapeutic relationship. In the absence of a well-established factor, the proportion of voluntary patients on a ward was chosen as a proxy measure of acuity and linked to therapeutic commitment.

Overall, the model under study hypothesizes that nurses' therapeutic commitment will be influenced by their experience, skills, knowledge and perceived legitimacy in that role. Factors in the practice environment such as leadership, collegial relationships, participation in the hospital, the foundations of quality care, clinical supervision, staffing, skill mix, and patient characteristics are also suggested to be associated with therapeutic commitment directly or through support and role competency. An overview of all concepts measured in this study is included in Table 1. 
Table 1: Definitions of Principal Variables

\begin{tabular}{|c|c|c|}
\hline VARIABLE & INSTRUMENT/DESCRIPTION & MEASUREMENT \\
\hline & NWI-PES & \\
\hline Nurse & Nurse Participation in Hospital Affairs & Continuous \\
\hline Participation & $\begin{array}{l}\text { - Opportunities for career development, participation in policy } \\
\text { decisions, involvement in hospital governance and hospital } \\
\text { committees. } \\
\text { - Nursing administration that listens and responds to staff concerns. }\end{array}$ & \\
\hline Nursing & Nursing Foundations for Quality of Care & Continuous \\
\hline Foundations & $\begin{array}{l}\text { - Access to staff development, continuing education and preceptor } \\
\text { programs for nurses. } \\
\text { - The facilitation of high quality nursing care, including high standards, } \\
\text { a nursing rather than medical philosophy, continuity of care, up to } \\
\text { date nursing care plans, and an active quality assurance program. }\end{array}$ & \\
\hline $\begin{array}{l}\text { Nurse } \\
\text { Leadership and } \\
\text { Support }\end{array}$ & $\begin{array}{l}\text { Nurse Manager Ability, Leadership, and Support of Nurses } \\
\text { - Supportive managers who acknowledge quality work, who are good } \\
\text { leaders and who support nurses in decision making. }\end{array}$ & Continuous \\
\hline $\begin{array}{l}\text { Staffing and } \\
\text { Resource } \\
\text { Adequacy }\end{array}$ & $\begin{array}{l}\text { Staffing and Resource Adequacy } \\
\text { - Sufficient resources to provide quality patient care, including } \\
\text { adequate staffing and appropriate skill mix, opportunities to discuss } \\
\text { patient care with colleagues and support services to permit more } \\
\text { patient contact. }\end{array}$ & Continuous \\
\hline $\begin{array}{l}\text { Nurse - Doctor } \\
\text { Relations }\end{array}$ & $\begin{array}{l}\text { Collegial Nurse - Physician Relationships } \\
\text { - Teamwork, collaboration and good working relationships between } \\
\text { doctors and nurses. }\end{array}$ & Continuous \\
\hline $\begin{array}{l}\text { Therapeutic } \\
\text { Commitment }\end{array}$ & $\begin{array}{l}\text { MHPPQ } \\
\text { - The level of commitment on behalf of those providing care to engage } \\
\text { therapeutically with the patient, including non-judgemental } \\
\text { acceptance, empathy, and a genuine desire to help. }\end{array}$ & Continuous \\
\hline $\begin{array}{l}\text { Role } \\
\text { Competency }\end{array}$ & $\begin{array}{l}\text { - The nurse's perception of their own legitimacy in working with mental } \\
\text { health patients, together with their belief that they have adequate } \\
\text { skills and knowledge. }\end{array}$ & Continuous \\
\hline Role Support & $\begin{array}{l}\text { - The perception by the nurse that they have access to sufficient } \\
\text { support from their organisation. }\end{array}$ & Continuous \\
\hline $\begin{array}{l}\text { Nurse } \\
\text { Qualifications }\end{array}$ & $\begin{array}{l}\text { Nurse Characteristics } \\
\text { - Highest mental health qualification }\end{array}$ & Ordinal scale \\
\hline $\begin{array}{l}\text { Nurse } \\
\text { Experience }\end{array}$ & - Years worked in mental health & Continuous \\
\hline $\begin{array}{l}\text { Clinical } \\
\text { Supervision }\end{array}$ & - Currently receiving clinical supervision & Dichotomous \\
\hline Staffing & $\begin{array}{l}\text { Unit Characteristics } \\
\text { - Patient: Staff ratio }\end{array}$ & Continuous \\
\hline Skill Mix & - Percentage of registered nurses & Continuous \\
\hline $\begin{array}{l}\text { Patient } \\
\text { Turnover }\end{array}$ & $\begin{array}{l}\text { - Total patient movements (admissions, discharges and transfers) per } \\
\text { day }\end{array}$ & Continuous \\
\hline $\begin{array}{l}\text { Voluntary } \\
\text { Patients }\end{array}$ & - Percentage of voluntary patients & Continuous \\
\hline
\end{tabular}




\section{Method}

This study was undertaken using a model testing design, where the proposed model was examined using cross-sectional data. Data were collected using a nurse survey and ward (nursing unit) profile developed for this study. The model was tested using the Partial Least Squares Path Modeling (PLS-PM) approach (Tenenhaus et al., 2005; see Analysis, below).

\section{Setting, Sample \& Procedure}

Data were collected through a convenience sample of nurses and nursing units (wards): six mental health wards attached to five public general acute hospitals in metropolitan areas of New South Wales (NSW), Australia. The sample was taken for a period of 14 days per ward, between November 2005 and March 2006. Ethics approval was gained from the University and participating health services.

All RNs and ENs on the participating wards $(n=149)$ were invited to complete the anonymous survey. Ward profile data were collected by researchers concurrently for the 14-day period on each ward. A briefing was conducted by the researchers at the commencement of the data collection period and three follow-up phone calls were made to each ward to describe the study to nurses not present. Surveys were provided to nurses at the briefing and a supply left at the nurses' station. The survey was returned via reply-paid post.

As there is no accepted single technique for calculating sample size with PLS-PM (Marcoulides and Saunders, 2006), this was estimated using the 'rule of thumb' described by Chin, Marcolin and Newsted (2003): 'ten times the largest number of structural paths directed at a particular construct in the structural model'. In the current model, role support had eight paths, giving a desired sample size of 80 . A slightly smaller than desired nurse sample of 76 was achieved (response rate $51 \%$ ). Ward profiles provided the complete 84 days of data.

\section{Instruments \& Measurement}

Nurse Survey. The nurse survey included the Practice Environment Scale of the Nursing Work Index (NWI-PES; Lake, 2002), the Mental Health Problems Perception Questionnaire (MHPPQ; Lauder et al., 2000) and questions regarding the nurse's age, years experience in mental health nursing and qualifications in mental health. Age and experience were recorded as continuous variables, while qualification was an ordinal scale from 'no qualification' to 'PhD'. Clinical supervision was a dichotomous variable in response the question 'I am currently in receipt of clinical supervision.' These questions were adapted from previous research in Australia (Duffield et al., In Press, White and Roche, 2006). 
The NWI-PES has been used widely (Warshawsky and Havens, 2011). It was derived from the Revised Nursing Work Index (Aiken and Patrician, 2000), which was in turn developed from earlier work in the United States (Kramer and Hafner, 1989). The 31 items in the NWI-PES are scored on a 4point scale, with higher scores indicating agreement that the item is present in the environment. The instrument measures 5 domains (Table 1): Collegial nurse-doctor relationships; Nurse manager ability, leadership, and support of nurses; Nursing foundations for quality of care; Nurse participation in hospital affairs; and Staffing and resource adequacy (Lake, 2002). In application to mental health nurses, a similar five-factor scale was found by Hanrahan (2007), although with different rankings and loadings of some items compared to medical and surgical nurses. Internal consistency has been found to be satisfactory for each of the subscales and the instrument as a whole (Cronbach's a $0.70-0.98$; Lake and Friese, 2006, Roche and Duffield, 2010, Warshawsky and Havens, 2011).

The MHPPQ was initially developed for investigating the role of rural district nurses in the United Kingdom (Angus et al., 2001, Lauder et al., 2000). This 27 item instrument was adapted from the Alcohol and Alcohol Problems Perception Questionnaire developed in the 1980s (Cartwright, 1981, Cartwright, 1980, Shaw et al., 1978). Responses are scored on a 7 point scale from 1 to 7 with higher scores indicating stronger agreement with each statement.

Three subscales have been described (Cartwright, 1980, Lauder, et al., 2000; Lauder, et al., 2002). The first is therapeutic commitment, including items such as 'I want to work with patients with mental health problems' and 'I feel that I have something to offer patients with mental health problems.' Role competency includes 'I have the skills to work with patients with mental health problems' and 'I feel that I can appropriately advise my patients about mental health problems'. Role support examples are: 'If I felt the need when working with patients with mental health problems I could easily find someone with whom I could discuss any difficulties I might encounter' and 'When working with patients with mental health problems I receive adequate supervision from a more experienced person'. Construct validity has been established for these domains, accounting for over $50 \%$ of total variance, and internal consistency has been estimated with Cronbach's $\alpha$ between 0.83 and 0.91 (Angus et al., 2001, Angus et al., 2001, Lauder et al., 2000).

Ward profile. The ward profile was adapted from previous Australian research (Duffield et al., In Press). It captured the number of admissions, transfers and discharges per day; the number of voluntary and involuntary patients per day; and the number of RNs, ENs and Assistants in Nursing (AIN; similar to Patient Care Assistants) per shift. The variables skill mix (percentage of RNs), unit staffing (patients per nurse), patient turnover (total admissions, transfers and discharges) and voluntary patients (percentage of voluntary patients) were calculated from these data (Table 1). 
Analysis

Data were analyzed using SPSS version 16 (SPSS Inc., 2007) and SmartPLS version 2 (Ringle et al., 2005). SmartPLS software was developed for the design and testing of path models using a partial least squares technique. A graphical user interface permits users to draw constructs and paths, with individual data items added to the constructs using a 'drag and drop' approach. SmartPLS simultaneously determines indirect and direct path influences among all of the latent variables in a model (Temme, et al., 2006; see also http://www.smartpls.de).

The ward data were complete. Seven nurse surveys had up to 2 missing responses to some questions in the MHPPQ or NWI-PES. No item was missing on more than two surveys. Missing values were replaced with the mean of the individual's responses to items of the same domain in the instrument. Although this approach reduces variance, it is a common technique in the social sciences, noted to perform more effectively than regression or other approaches with small sample sizes (Roth et al., 1999). This approach is also the only imputation function available in the SmartPLS software (Temme et al., 2006).

Descriptive statistics were first calculated, distributions examined, and the sample data compared to the population of nurses working in mental health in NSW and prior research. Ward staffing, skill mix, patient legal status and patient turnover figures were aggregated to the ward level and linked to individual nurse data. Continuous variables were transformed into z-scores in order to undertake the PLS-PM process (Tenenhaus et al., 2005).

Modeling. Partial least squares path modeling describes the relationships between observed or measured variables and theoretical constructs. The technique requires the development of a conceptually derived model that proposes relationships between a set of variables (see Figure 1). PLS-PM is suitable for model testing using small samples and relatively high numbers of variables (Cassel et al., 1999, Chin et al., 2003). It may be used with categorical or continuous data and is only moderately sensitive to multicollinearity and skewed distributions (Falk and Tonkin, 2001, Hsu et al., 2006, Sellin, 1995). In this study, PLS-PM was conducted in an iterative exploratory mode by first testing the model against a priori criteria; removing paths or variables; and then testing the revised model (Chin, 1998, Falk and Tonkin, 2001, Sellin, 1995). The final model provided estimates of the strength and statistical significance of the relationships between concepts.

Criteria for the retention of constructs in the model were developed in accordance with PLSPM practice. These were:

- Satisfactory convergent and discriminant validity as indicated by factor loadings above 0.6 (a lower threshold than applied in other analyses is often adopted in PLS-PM; Chin, 
1998), average variance explained (AVE) above 0.5 (Fornell and Larcker, 1981), statistically significant ( $p \leq 0.05$ ) t-statistics (Gefen and Straub, 2005, Ringle et al., 2005), high correlation of items with their designated construct (Gefen and Straub, 2005, Tenenhaus et al., 2005), and a correlation between items and their designated construct higher than the square root of the AVE (Fornell and Larcker, 1981);

- Composite reliability $\left(p_{c}\right)$ or Cronbach's alpha $(\alpha)$ above 0.7 (Chin and Marcolin, 1995, Tenenhaus et al., 2005, Werts et al., 1974). Composite reliability is a measure of internal consistency that permits different measurement scales, different degrees of precision and different amounts of error for items measuring the same latent variable. This is in contrast to the more stringent Cronbach's alpha (Graham, 2006). Composite reliability values above 0.7 are considered acceptable (Hair, et al., 1998);

- A positive value for the Stone-Geisser $Q$ test of predictive relevance $\left(Q^{2} ;\right.$ Sellin, 1995 , Tenenhaus et al., 2005). This figure is calculated by omitting one case from the analysis, predicting this case from the remaining cases, and repeating this process for all cases. $Q^{2}$ values should be above 0 (Fornell \& Bookstein, 1982; Sellin,1995);

- Consideration of the combined statistical significance $(p \leq 0.05)$ and size $(>0.2)$ of the standardized path estimate, and contribution $(>1.5 \%)$ to the total amount of variance in the dependent construct (Falk and Tonkin, 2001, Tenenhaus et al., 2005, Wong, 2006).

\section{Results}

Nurse Demographics

Respondents were predominantly female (68.4\%) registered nurses $(89.5 \%)$ working full time $(72.4 \%)$, with a mean age of 36.3 years and an average 8.2 years of mental health nursing (Table 2 ). These were generally similar to national data (AIHW, 2008), although this group was noticeably younger than the population average of 44.3 years. Twenty-six nurses (34.2\%) had no qualifications in mental health, concordant with previous research in this state (White and Roche, 2006), and national figures (Australian Mental Health Workforce Advisory Committee, 2008). About one-third indicated they had completed a post-graduate qualification and the remainder possessed hospitalbased certificates in mental health. Twenty five nurses (32.9\%) were currently in receipt of clinical supervision, again consistent with the findings of White and Roche (2006). 
Table 2: Nurse \& Ward Characteristics

\begin{tabular}{lc}
\hline Nurse Characteristics (N=76) & Mean (SD) \\
\hline Age & $36.3(10.56)$ \\
Years Nursing in Mental Health & $8.2(7.62)$ \\
\hline Sex & $\mathbf{N}(\%)$ \\
$\quad$ Female & $52(68.4 \%)$ \\
Male & $24(31.6 \%)$ \\
Employment Status & \\
Full time & $55(72.4 \%)$ \\
Part time & $16(21.1 \%)$ \\
Casual & $5(6.6 \%)$ \\
Grade & \\
Registered Nurse & $68(89.5 \%)$ \\
Enrolled Nurse* & $8(10.5 \%)$ \\
Mental Health Qualification & \\
No Qualification & $26(34.2 \%)$ \\
Hospital Certificate (basic qualification) & $17(22.4 \%)$ \\
Post-basic Certificate & $18(23.7 \%)$ \\
Graduate Diploma & $12(15.8 \%)$ \\
Master Degree & $3(3.9 \%)$ \\
Other & \\
Receiving Clinical Supervision & $25(32.9 \%)$ \\
\hline Ward Characteristics (N=84 Ward-days) & Mean (SD) \\
\hline Registered Nurse \% & $75.3(18.08)$ \\
Patients per nurse per shift & $4.2(1.71)$ \\
Patient movements per day & $3.8(3.36)$ \\
Voluntary patients \% & $44.6(28.76)$ \\
\hline
\end{tabular}

* EN: similar to LVN/LPN in the United States

The Practice Environment Scale of the Nursing Work Index

The means for all subscales of the NWI-PES were above 2.5 and therefore in the positive range as described by Lake and Friese (2006). Subscales scored higher than in previous work with psychiatric nurses in the United States (Hanrahan et al., 2010), with the exception of foundations which scored lower (Table 3). The scores were distributed normally, but were more widely dispersed than in previous research using this instrument; possibly a consequence of the sample size.

Internal consistency figures met criteria (Table 3), although nursing foundations for quality of care displayed a low Cronbach's alpha (0.53). This finding may be an artefact of the small sample size (Marcoulides and Saunders, 2006) or a response peculiar to this sample. Further testing of the NWIPES with a larger and more diverse sample of Australian nurses working in mental health area may clarify this. The subscale did display a satisfactory composite reliability figure of 0.74 so was retained for model testing (Chin, 1998, Chin and Gopal, 1995, Werts et al., 1974). 


\section{The Mental Health Problems Perception Questionnaire}

The average subscale scores for therapeutic commitment (81.5; SD=9.07) and role competency (52.5; SD=7.42) were substantially higher than in Lauder and colleagues' (2002) study which found therapeutic commitment of 67.1 ( $S D=10.2$ ) and role competency 34.3 (SD=7.5). Role support (20.6; SD=3.97) was slightly higher in the current study than in that research $(19.1 ; S D=3.6)$. Data displayed a mild negative skew, but none were highly distorted. Parameter estimates were within the nominated range (Table 3).

Table 3: NWI-PES \& MHPPQ Scores, Internal Consistency \& Validity

\begin{tabular}{lcccc}
\hline Scale, Domain (Possible Range) & Mean (SD) & $\boldsymbol{\alpha} / \mathbf{p}_{\mathbf{c}}{ }^{+}$ & $\begin{array}{c}\text { Average } \\
\text { Variance } \\
\text { Explained }\end{array}$ & $\begin{array}{c}\text { Factor } \\
\text { Loadings } \\
\text { (range) }\end{array}$ \\
\hline NWI-PES (1-4) & & & & \\
$\quad$ Collegial Nurse - Physician Relationships & $3.1(0.62)$ & $0.85 / 0.91$ & 0.77 & $0.83-0.91$ \\
$\quad$ Nurse Manager Ability, Leadership, \& Support & $2.7(0.75)$ & $0.80 / 0.87$ & 0.62 & $0.68-0.83$ \\
$\quad$ Staffing and Resource Adequacy & $2.6(0.62)$ & $0.80 / 0.87$ & 0.63 & $0.71-0.83$ \\
$\quad$ Nurse Participation in Hospital Affairs & $2.5(0.49)$ & $0.70 / 0.81$ & 0.51 & $0.62-0.87$ \\
$\quad$ Nursing Foundations for Quality of Care & $2.6(0.39)$ & $0.53 / 0.74$ & 0.50 & $0.60-0.72$ \\
\hline MHPPQ & & & & \\
$\quad$ Therapeutic Commitment (14-98) & $81.5(9.07)$ & $0.86 / 0.91$ & 0.51 & $0.61-0.80$ \\
$\quad$ Role Support (4-28) & $20.6(3.97)$ & $0.81 / 0.88$ & 0.66 & $0.61-0.90$ \\
$\quad$ Role Competency (9-63) & $52.5(7.42)$ & $0.91 / 0.93$ & 0.70 & $0.60-0.91$ \\
\hline
\end{tabular}

$\dagger \alpha=$ Cronbach's alpha; $\mathrm{pc}=$ Composite Reliability

Wards

Wards ranged in size from 9 to 30 beds and RNs made up the majority of the workforce on most ward-days with a minimum of $35 \%$ on one day (Table 2). Enrolled Nurses and AINs generally made up a small proportion of clinical nurses although with the latter forming up to $56 \%$ of staffing in one instance. Overall staffing and patient turnover varied widely, with patient to nurse ratios ranging from 0.8 to 9.3 (mean 4.2 SD 1.71) and patient turnover per day from zero to 16 (mean 3.8 SD 3.36).

Individual patient characteristics were not collected and legal status was collated from ward records. The majority of patients were admitted involuntarily under the NSW Mental Health Act 1990 , with a wide variation across units (mean $=55.4 \%, S D=28.76$ ). This proportion was higher than the figure reported nationally for acute public hospitals during the same period (41.4\%), although the national figure included one state (not the current one) with only $2 \%$ of involuntary patient admissions (AlHW, 2008). However, as legal status has been used as a proxy for acuity in this study, this suggests a slightly higher proportion of higher acuity patients. 


\section{Model Testing}

Following the iterative PLS-PM procedure six latent variables and nine paths were removed, leaving a substantially smaller model than that originally proposed. The remaining variables and paths had a substantial relationship to their respective dependent variables. All paths were statistically significant except that from clinical supervision to role support. However, it met other criteria for retention in accordance with the approach described by Falk and Tonkin (2001). The final model is described in Table 4.

Table 4 Summary of Model Testing

\begin{tabular}{lccc}
\hline Variable & $\begin{array}{c}\text { Role Support } \\
\boldsymbol{\beta}\left(\% \mathbf{R}^{2}\right)\end{array}$ & $\begin{array}{c}\text { Role Competency } \\
\boldsymbol{\beta}\left(\% \mathbf{R}^{2}\right)\end{array}$ & $\begin{array}{c}\text { Therapeutic } \\
\text { Commitment } \\
\boldsymbol{\beta}\left(\% \mathbf{R}^{2}\right)\end{array}$ \\
\hline $\mathbf{Q}^{2}$ & $\mathbf{0 . 2 3}$ & $\mathbf{0 . 2 4}$ & $\mathbf{0 . 2 3}$ \\
\hline $\mathbf{R}^{2}$ & $\mathbf{0 . 4 0}$ & $\mathbf{0 . 3 8}$ & $\mathbf{0 . 5 5}$ \\
\hline Nurse Participation & removed & $0.38^{* *}(8.4 \%)$ & \\
$\begin{array}{l}\text { Nursing Foundations } \\
\text { Nurse Leadership and Support }\end{array}$ & $\begin{array}{c}0.54^{* *}(31.2 \%) \\
\text { removed }\end{array}$ & $-0.30^{*}(7.1 \%)$ & \\
Staffing and Resource & removed & & $0.63^{* *}(45.2 \%)$ \\
Adequacy & removed & & $0.21^{* *}(9.3 \%)$ \\
Nurse - Doctor Relations & & & \\
Role Competency & & $0.31^{* *}(11.7 \%)$ & \\
Role Support & removed & \\
Nurse Qualifications & & $0.33^{* *}(11.1 \%)$ & \\
Nurse Experience & removed & \\
Clinical Supervision & & & removed \\
Staffing & & & removed \\
Skill Mix & $0.16^{\text {ns }}(3.5 \%)$ & & \\
Patient Turnover & removed & & \\
Voluntary Patients & $-0.23^{* *}(4.8 \%)$ & & \\
\hline
\end{tabular}

$\beta=$ Standardized Path Coefficient; $\% R^{2}=$ the proportion of variance explained by this variable in the dependent variable

$\mathrm{Q}^{2}=$ predictive relevance; $\mathrm{R}^{2}=$ total proportion of variance explained of the dependent variable ${ }^{*}$ Significant at $\mathrm{p} \leq 0.05 ;{ }^{* *}$ Significant at $\mathrm{p} \leq 0.01 ; \mathrm{ns}=$ Not Significant

'removed' indicates that the item did not meet criteria for retention in the final model

\section{Final Model}

Role competency had an $R^{2}$ of 0.38 , with good predictive relevance $\left(Q^{2}\right)$ of 0.24 . Role support was the strongest influence on role competency (11.7\%), closely followed by the nurse's experience in mental health $(11.1 \%)$, with the nurse's participation in hospital affairs and their perception of nurse leadership contributing smaller proportions. Leadership displayed a negative value $(\beta=-0.30)$.

Only three variables in the final model were linked to role support $\left(R^{2}=0.40 ; Q^{2}=0.23\right)$. The largest contribution was made by the nursing foundations for quality of care (31.2\%) followed by 
skill mix and clinical supervision. The path between skill mix and role support was negative $(\beta=-0.23)$ and the path from clinical supervision to role support was not statistically significant $(p=0.08)$.

The ultimate dependent variable in this model, therapeutic commitment, was associated with role competency and role support. The former construct was by far the most influential here $(45.2 \%$; $\left.R^{2}=0.55 ; Q^{2}=0.23\right)$, with role support accounting for $9.3 \%$ of the variance.

Overall, the core framework was supported in accordance with previous research (Lauder et al., 2002). Several of the added factors were major contributors to the final model, particularly foundations, experience, and participation in hospital affairs, while leadership, skill mix and clinical supervision were less influential. A number of constructs and paths specified in the initial model did not meet criteria and were removed.

\section{Discussion}

This study has explored a model of relationships between environmental factors and the nurses' ability and willingness to engage therapeutically with patients in the acute inpatient mental health setting. Role support, role competency and therapeutic commitment were related, and several characteristics of the individual and environment were associated with these factors. In accordance with the initial aims of the study, factors in the practice environment were found to be linked to therapeutic commitment. However, the final model was substantially reduced. Therefore, the model as originally specified may be considered a limited success in proposing important factors, the links between them, and their influence on nurses' therapeutic commitment.

The finding that experience was a strong influence on role competency is consistent with prior studies (Airey and Marriott, 2003, Albery et al., 2003). However, clinical supervision was not associated with role competency and was only a minor influence on support. This suggests that clinical supervision was seen as a moderately supportive activity rather than one that develops skills and knowledge, as in the Proctor model (Proctor, 1986). Respondents may have been in receipt of supervision with an emphasis on support, or only the supportive aspects of clinical supervision were associated with the concept. Additional information on the type and frequency of the process would add to future work.

Conversely, participation in hospital affairs was considered to enhance role competency rather than to provide support. In addition, the mean score was higher than in other studies (Hanrahan et al., 2010, Roche and Duffield, 2010), suggesting that there was already a reasonable degree of involvement at the hospital level, particularly in relation to activities linked to role competency such as career development, in contrast to anecdotal reports (Mental Health Council of Australia, 2005). Nursing leadership was also not associated with role support and was negatively 
related to role competency. This is different to previous findings (Aiken et al., 2008, Hanrahan et al., 2010, Schmalenberg and Kramer, 2008) and, based on reports to the Mental Health Council of Australia (2005) suggesting mental health services may have limited involvement in hospital leadership, may indicate a mixed view of general hospital and mental health ward leadership in these mainstreamed services.

Nursing foundations had a strong association with role support; in accordance with research that has identified access to preceptorship, the expectation of high standards and a nursing model of care as important elements (Hayman-White et al., 2007, Tervo-Heikkinen et al., 2008). However, this finding should be considered in concert with the low Cronbach's alpha score, which suggests the construct needs further examination in this context.

Staffing was not a significant factor, suggesting that it was at adequate levels. For example, the staffing and resource adequacy subscale score was higher than in other Australian research (Middleton et al., 2008, Roche and Duffield, 2010) and the mean patient to nurse ratio was better than that reported by Hanrahan et al. (2010) for psychiatric units. Similarly, nurse-doctor relationships scored very highly and the construct was not associated with role support. This may be a consequence of overall good relationships, as reported in some mental health settings (Gaskin et al., 2007).

Skill mix had a negative association with role support. This factor has been consistently linked to positive patient and nurse outcomes in general nursing (Lankshear et al., 2005, Roche et al., 2010) and the finding is therefore difficult to explain. It may be a consequence of the small sample size (Marcoulides et al., 2009), or different constructs such as nurse-physician ratio or psychologists per nurse may better reflect skill mix in a multidisciplinary mental health system (Halsteinli et al., 2008, Hughes et al., 2008).

In contrast to previous work (Aiken et al., 2003, Hughes et al., 2008), qualifications were not retained in this model. It is feasible that the variable as measured here may not capture the key aspects of this factor and that additional exploration is required. Finally, patient turnover and the proportion of voluntary patients were not retained. Although it is possible that they are not influential factors, other possibilities include issues related to sample size, the low rate of patient turnover in this study, and that legal status may not be a valid proxy for mental state. Further research is required to validate these factors, or to establish alternatives.

Together, these findings suggest that services should improve the support provided to clinical nurses and to their ability to engage in the therapeutic relationship through improving aspects of nursing foundations, participation in hospital affairs, supported experience, and to a lesser degree clinical supervision. Less clear is the potential influence of enhanced mental health leadership, richer 
skill mix, reduced patient turnover and patient characteristics, although these would benefit from further and more detailed study to clarify their level and direction of influence.

\section{Limitations}

The primary limitation of the study was the small sample size, which may explain the nonsignificance of relationships between some constructs (Hsu et al., 2006), issues regarding validity and reliability, and the unexpected effects of leadership and skill mix (Marcoulides et al., 2009). Also, the sample size did not allow examination of data clustering through segmentation or alternative models (Esposito-Vinzi et al., 2008).

A number of sub-scales met the criteria for inclusion, but exhibited lower than ideal Cronbach's alpha scores, AVE, factor loadings or path coefficients. In particular, the internal consistency of the NWI-PES subscale 'foundations' is low. This could be related to the sample size or could suggest that the domain is not valid in this context. However, the latter possibility is in contrast to both Hanrahan's (2007) findings with psychiatric nurses in the United States and Australian research using the NWI-PES (Duffield et al., In Press, Middleton et al., 2008), suggesting that the sample size might be the primary issue.

In addition, nurse qualifications were included in the initial model but grade was not, so that the potential impact of different roles was not examined, and although engagement may be influenced by the patients' mental state, data describing this were not available.

Overall, this study has identified several factors in the environment that are associated with therapeutic commitment. Future examination of the proposed model with a larger sample and the improved measurement of some constructs may provide a stronger analysis and more detailed information regarding the specific influence of these factors.

\section{Conclusion}

A substantial body of research has established the relationship of characteristics of the practice environment with patient and nurse outcomes. A key requirement in further developing an understanding of these relationships in mental health is the identification of the relative influence of the variables on the nurse's work. Despite the limitations noted above, this study suggests that individual and practice environment factors do impact on nurses' ability and willingness to engage in the therapeutic relationship, a critical aspect of the nurse's role in mental health. Targeted approaches to workplace support, development and continued education of nurses in mental health may enhance the environment, with potential positive outcomes for nurses and patients. Further examination of the influence of the factors and their relationships is warranted. 


\section{References}

AlHW, 2004. Mental Health Services in Australia 2001-02. In: Mental Health Series. Canberra.

AlHW, 2008. Mental Health Services in Australia 2005-06. In: Mental Health Series. Australian Institute of Health and Welfare, Canberra.

AlHW, 2010a. Mental Health Services in Australia 2007-08. In: Mental Health Series. Australian Institute of Health and Welfare, Canberra.

AlHW, 2010b. National health data dictionary. Version 15 In: National Health Data Dictionary Series. Australian Institute of Health and Welfare, Canberra.

AlHW, 2008. Nursing and Midwifery Labour Force 2005. In: National Health Labour Force Series. Australian Institute of Health and Welfare, Canberra.

Aiken, L.H., Clarke, S.P., Cheung, R.B., Sloane, D.M., Silber, J.H., 2003. Educational levels of hospital nurses and surgical patient mortality. Journal of the American Medical Association 290 (12), 1617-1623.

Aiken, L.H., Clarke, S.P., Sloane, D.M., Lake, E.T., Cheney, T., 2008. Effects of hospital care environment on patient mortality and nurse outcomes. Journal of Nursing Administration 38 (5), 223-229.

Aiken, L.H., Clarke, S.P., Sloane, D.M., Sochalski, J., 2001. Cause for concern: Nurses' reports of hospital care in five countries. LDI Issue Brief 6 (8), 1-4.

Aiken, L.H., Clarke, S.P., Sloane, D.M., Sochalski, J., Silber, J.H., 2002. Hospital nurse staffing and patient mortality, nurse burnout, and job dissatisfaction. Journal of the American Medical Association 288 (16), 1987-1993.

Aiken, L.H., Patrician, P.A., 2000. Measuring organizational traits of hospitals: The Revised Nursing Work Index. Nursing Research 49 (3), 146-153.

Airey, N., Marriott, J., 2003. Measuring therapeutic attitudes in the prison environment: Development of the Prison Attitude to Drugs scale. Addiction 98 (2), 179.

Albery, I.P., Heuston, J., Ward, J., Groves, P., Durand, M.A., Gossop, M., Strang, J., 2003. Measuring therapeutic attitude among drug workers. Addictive Behaviors 28 (5), 995-1005.

Alexander, J.A., Lichtenstein, R., Jinnett, K., Wells, R., Zazzali, J., Liu, D., 2005. Cross-functional team processes and patient functional improvement. Health Services Research 40 (5), 1335-1355.

Altschul, A.T., 1972. Patient-Nurse Interaction. Churchill Livingstone, Edinburgh.

Angus, N.J., Lauder, W., Reynolds, W., 2001. Further testing of the Mental Health Problems Perception Questionnaire. Journal of Advanced Nursing 33 (5), 638.

Angus, N.J., Lauder, W., Reynolds, W., 2001. Psychometric development of the Mental Health Problems Perception Questionnaire. Journal of Psychiatric \& Mental Health Nursing 8 (5), 471-472.

Armstrong, K., Laschinger, H.K.S., Wong, C., 2009. Workplace empowerment and magnet hospital characteristics as predictors of patient safety climate. Journal of Nursing Care Quality 24 (1), 55-62.

Australian Health Workforce Advisory Committee, 2003. Australian Mental Health Nurse Supply, Recruitment and Retention. AHWAC, Sydney.

Australian Mental Health Workforce Advisory Committee, 2008. Mental Health Workforce: Supply of Mental Health Nurses. AMHWAC, Canberra.

Bandura, A., 2001. Social cognitive theory: An agentic perspective. Annual Review of Psychology 52 (1), 1-26.

Barker, P.J., 1990. The conceptual basis of mental health nursing. Nurse Education Today 10 (5), 339-348.

Barker, P.J., Jackson, S., Stevenson, C., 1999. What are psychiatric nurses needed for? Developing a theory of essential nursing practice. Journal of Psychiatric and Mental Health Nursing 6 (2), 273-282.

Bjørngaard, J.H., Ruud, T., Friis, S., 2007. The impact of mental illness on patient satisfaction with the therapeutic relationship. Social Psychiatry and Psychiatric Epidemiology 42 (10), 803-809.

Bowers, L., Nijman, H., Simpson, A., Jones, J., 2010. The relationship between leadership, teamworking, structure, burnout and attitude to patients on acute psychiatric wards. In: Social Psychiatry and Psychiatric Epidemiology. Springer, pp. 1-6.

Brennan, G., Flood, C., Bowers, L., 2006. Constraints and blocks to change and improvement on acute psychiatric wards lessons from the City Nurses project. Journal of Psychiatric and Mental Health Nursing 13 (5), 475-482.

Brown, S.P., Jones, E., Leigh, T.W., 2005. The attentuating effect of role overload on relationships linking self-efficacy and goal level to work performance. Journal of Applied Psychology 90 (5), 972-979. 
Butterworth, T., Carson, J., Jeacock, J., White, E., Clements, A., 1999. Stress, coping, burnout and job satisfaction in British nurses: findings from the clinical supervision evaluation project. Stress Medicine 15 (1), 27-33.

Cartwright, A.K.J., 1981. Are different therapeutic perspectives important in the treatment of alcoholism? British Journal of Addiction 76 (4), 347-361.

Cartwright, A.K.J., 1980. The attitudes of helping agents towards the alcoholic client: The influence of experience, support, training, and self-esteem. British Journal of Addiction 73, 413-431.

Cassel, C.M., Hackl, P., Westlund, A.H., 1999. PLS for estimating latent variable quality structures: Finite sample robustness properties. Journal of Applied Statistics 26 (4), 435-446.

Chang, Y.-K., Mark, B.A., 2009. Antecedents of severe and nonsevere medication errors. Journal of Nursing Scholarship 41 (1), 70-78.

Chin, W.W., 1998. Issues and opinion on structural equation modeling. MIS Quarterly 22 (1), 7-16.

Chin, W.W., Gopal, A., 1995. Adoption intention in GSS: relative importance of beliefs. The DATA BASE for Advances in Information Systems 26 (2-3), 42-64.

Chin, W.W., Marcolin, B.L., 1995. The holistic approach to construct validation in research: Examples of the interplay between theory and measurement. In: Administrative Sciences Association of Canada - 23rd Conference - IS Proceedings. Administrative Sciences Association of Canada, Windsor, Ontario, pp. 33-43.

Chin, W.W., Marcolin, B.L., Newsted, P.R., 2003. A partial least squares latent variable modeling approach for measuring interaction effects: Results from a Monte Carlo simulation study and an electronic mail emotion/adoption study. Information Systems Research 14 (2), 189-217.

Cleary, M., Edwards, C., 1999. Something always comes up: Nurse-patient interaction in an acute psychiatric setting. Journal of Psychiatric and Mental Health Nursing 6 (6), 469-477.

Coleman, J.C., Paul, G.L., 2001. Relationship between staffing ratios and effectiveness of inpatient psychiatric units. Psychiatric Services 52 (10), 1374.

Coleman, M., Jenkins, E., 1998. Developments in mental health nursing: A critical voice. Journal of Psychiatric and Mental Health Nursing 5 (5), 355-359.

Department of Health and Ageing, 2009. National Mental Health Policy 2008. Commonwealth of Australia, Canberra.

Donat, D.C., 2002. Impact of staffing on seclusion/restraint reliance. Psychiatric Rehabilitation Journal 25 (4), 413-417.

Duffield, C.M., Diers, D., O'Brien-Pallas, L., Aisbett, C., Roche, M.A., King, M.T., Aisbett, K., In Press. Nursing staffing, nursing workload, the work environment and patient outcomes. Applied Nursing Research Published Online 11 February 2010.

Duffield, C.M., Diers, D.K., Aisbett, C., Roche, M.A., 2009. Churn: Patient turnover and casemix. Nursing Economic\$27 (3), 185-191.

Duffield, C.M., Roche, M.A., O'Brien-Pallas, L.L., Catling-Paull, C., King, M.T., 2009. Staff satisfaction and retention and the role of the Nursing Unit Manager. Collegian 16 (1), 11-17.

Dziopa, F., Ahern, K., 2009. What makes a quality therapeutic relationship in psychiatric/mental health nursing: A review of the research literature. Internet Journal of Advanced Nursing Practice 10 (1), 7-7.

Esposito-Vinzi, V., Trinchera, L., Squillacciotti, S., Tenenhaus, M., 2008. REBUS-PLS: A response-based procedure for detecting unit segments in PLS path modelling. Applied Stochastic Models in Business and Industry 24 (5), $422-$ 441.

Falk, R.F., Tonkin, P., 2001. Soft modelling the predictors of drug treatment use. In: Social Research Update. University of Surrey, Guidlford, United Kingdom, pp. 1-4.

Forchuk, C., Reynolds, W., 2001. Clients' reflections on relationships with nurses: comparisons from Canada and Scotland. Journal of Psychiatric \& Mental Health Nursing 8, 45-51.

Fornell, C., \& Bookstein, F. L., 1982. Two structural equation models: LISREL and PLS applied to consumer exit-voice theory. Journal of Marketing Research, 19, 440-452.

Fornell, C., Larcker, D.F., 1981. Evaluating structural equation models with unobservable variables and measurement error. Journal of Marketing Research 18 (1), 39-50.

Forsyth, A., 2007. The effects of diagnosis and non-compliance attributions on therapeutic alliance processes in adult acute psychiatric settings. Journal of Psychiatric and Mental Health Nursing 14 (1), 33-40.

Garrosa, E., Moreno-Jiménez, B., Liang, Y., González, J.L., 2008. The relationship between socio-demographic variables, job stressors, burnout, and hardy personality in nurses: An exploratory study. International Journal of Nursing Studies 45 (3), 418-427.

Gaskin, C.J., Elsom, S., Happell, B., 2007 Interventions for reducing the use of seclusion in psychiatric facilities: Review of the literature. British Journal of Psychiatry 191 (4), 298-303. 
Gefen, D., Straub, D.W., 2005. A practical guide to factorial validity using PLS-Graph: Tutorial and annotated example. Communications of the Association for Information Systems 16 (1), 91-109.

Graham, J. M., 2006. Congeneric and (essentially) tau-equivalent estimates of score reliability. Educational and Psychological Measurement, 66(6), 930-944.

Gunnarsdóttir, S., Clarke, S.P., Rafferty, A.M., Nutbeam, D., 2007. Front-line management, staffing and nurse-doctor relationships as predictors of nurse and patient outcomes. A survey of Icelandic hospital nurses. International Journal of Nursing Studies 15, 1-9.

Hair, J. F., Anderson, R. E., Tatham, R. L., \& Black, W. C., 1998. Multivariate Data Analysis. New Jersey: Prentice-Hall.

Halsteinli, V., Karterud, S., Pedersen, G., 2008. When costs count: The impact of staff size, skill mix and treatment intensity on patient outcome for psychotherapeutic day treatment programmes. Health Policy 86 (2), 255-265.

Hanrahan, N., 2007. Measuring inpatient psychiatric environments: Psychometric properties of the Practice Environment Scale-Nursing Work Index (PES-NWI). International Journal of Psychiatric Nursing Research 12 (3), 1521-1528.

Hanrahan, N.P., Aiken, L.H., 2008. Psychiatric nurse reports on the quality of psychiatric care in general hospitals. Quality Management in Health Care 17 (3), 210-217.

Hanrahan, N.P., Aiken, L.H., McClaine, L., Hanlon, A.L., 2010. Relationship between Psychiatric Nurse Work Environments and Nurse Burnout in Acute Care General Hospitals. Issues in Mental Health Nursing 31 (3), 198-207.

Hanrahan, N.P., Kumar, A., Aiken, L.H., 2010. Adverse Events Associated With Organizational Factors of General Hospital Inpatient Psychiatric Care Environments. Psychiatric Services 61 (6), 569.

Hansen, C., Carryer, J., Budge, C., 2007. Public health nurses' views on their position within a changing health system. Nursing Praxis in New Zealand 23 (2), 14-26.

Hayman-White, K., Happell, B., Charleston, R., 2007. Transition to mental health nursing through specialist graduate nurse programs in mental health: A review of the literature. Issues in Mental Health Nursing 28 (2), 185-200.

Horvath, A.O., 2005. The therapeutic relationship: Research and theory. Psychotherapy Research 15 (1-2), 3-7.

Howgego, I.M., Yellowlees, P., Owen, C., Meldrum, L., Dark, F., 2003. The therapeutic alliance: The key to effective patient outcome? A descriptive review of the evidence in community mental health case management. Australian and New Zealand Journal of Psychiatry 37 (2), 169-183.

Hsu, S.-H., Chen, W.-H., Hsieh, M.-J., 2006. Robustness testing of PLS, LISREL, EQS and ANN-based SEM for measuring customer satisfaction. Total Quality Management \& Business Excellence 17 (3), 355-371.

Hughes, E., Wanigaratne, S., Gournay, K., Johnson, S., Thornicroft, G., Finch, E., Marshall, J., Smith, N., 2008. Training in dual diagnosis interventions (the COMO Study): Randomised controlled trial. BMC Psychiatry 8 (1), 12-21.

Hummelvoll, J.K., 1996. The nurse-client alliance model. Perspectives in Psychiatric Care 32 (4), 12-21.

Hyrkas, K., 2005. Clinical supervision, burnout, and job satisfaction among mental health and psychiatric nurses in Finland. Issues in Mental Health Nursing 26 (5), 531-556.

Kramer, M., Hafner, L.P., 1989. Shared values: impact on staff nurse job satisfaction and perceived productivity. Nursing Research 38 (3), 172-177.

Lake, E.T., 2002. Development of the Practice Environment Scale of the Nursing Work Index. Research in Nursing \& Health 25 (3), 176-188.

Lake, E.T., Friese, C.R., 2006. Variations in nursing practice environments: Relation to staffing and hospital characteristics. Nursing Research 55 (1), 1-9.

Lankshear, A.J., Sheldon, T.A., Maynard, A., 2005. Nurse staffing and healthcare outcomes: A systematic review of the international research evidence. Advances in Nursing Science 28 (2), 163-174.

Laschinger, H.K.S., Finegan, J., Wilk, P., 2009. Context matters: The impact of unit leadership and empowerment on nurses' organizational commitment. Journal of Nursing Administration 39 (5), 228-235.

Laschinger, H.K.S., Leiter, M.P., 2006. The impact of nursing work environments on patient safety outcomes: The mediating role of burnout/engagement. Journal of Nursing Administration 36 (5), 259-267.

Lauder, W., Reynolds, W., Reilly, V., Angus, N.J., 2000. The development and testing of the Mental Health Problems Perception Questionnaire. Journal of Psychiatric \& Mental Health Nursing 7 (3), 221-226.

Lauder, W., Reynolds, W., Smith, A., Sharkey, S., 2002. A comparison of therapeutic commitment, role support, role competency and empathy in three cohorts of nursing students. Journal of Psychiatric \& Mental Health Nursing 9 (4), 483.

Leiter, M.P., Laschinger, H.K.S., 2006. Relationships of work and practice environment to professional burnout: Testing a causal model. Nursing Research 55 (2), 137-146.

Marcoulides, G.A., Chin, W.W., Saunders, C., 2009. A critical look at partial least squares modeling. MIS Quarterly 33 (1), 171-175. 
Marcoulides, G.A., Saunders, C., 2006. PLS: A silver bullet? MIS Quarterly 30 (2), iii-ix.

Mental Health Council of Australia, 2005. Not For Service: Experiences of Injustice and Despair in Mental Health Care in Australia. MHCA, Canberra.

Middleton, S., Griffiths, R., Fernandez, R., Smith, B., 2008. Nursing practice environment: How does one Australian hospital compare with magnet hospitals? International Journal of Nursing Practice 14 (5), 366-372.

NSW Labour Economics Office, 2008. Registered Mental Health Nurse, NSW. In: Health Professions Occupational Reports. DEEWR, Sydney.

NSW Mental Health Sentinel Events Review Committee, 2005. Tracking Tragedy 2004: A Systemic Look at Homicide by Mental Health Patients and Suicide Death of Patients Recently Discharged from Mental Health Inpatient Units. Second report of the Committee. NSW Centre for Mental Health, North Sydney.

Pagnini, D., 2005. Review of the NSW Mental Health Nursing Enhancement Program. NSW Health, North Sydney.

Peplau, H., 1992. Interpersonal relations: A theoretical framework for application in nursing practice. Nursing Science Quarterly 5 (1), 13-18.

Peplau, H., 1997. Peplau's theory of interpersonal relations. Nursing Science Quarterly 10 (4), 162-167.

Peplau, H., 1989. Theory: the professional dimension. In: O'Toole, A.W., Welt, S.R. (Eds.), Interpersonal theory in nursing practice: selected works of Hildegard Peplau. Springer, New York.

Proctor, B., 1986. Supervision: a co-operative exercise in accountability. In: Marken, M., Payne, M. (Eds.), Enabling and Ensuring: Supervision in Practice. National Youth Bureau and Council for Education and Training in Youth and Community Work, Leicester.

Reynolds, W.J., Scott, B., 2000. Do nurses and other professional helpers normally display much empathy? Journal of Advanced Nursing 31 (1), 226.

Ringle, C.M., Wende, S., Will, S., 2005. SmartPLS. Hamburg

Roche, M.A., Diers, D., Duffield, C.M., Catling-Paull, C.J., 2010. Violence toward nurses, the work environment, and patient outcomes. Journal of Nursing Scholarship 42 (1), 13-22.

Roche, M.A., Duffield, C.M., 2010. A comparison of the nursing practice environment in mental health \& medical-surgical settings. Journal Of Nursing Scholarship 42 (2), 195-206.

Rogers, C., 1957. The necessary and sufficient conditions of therapeutic personality change. Journal of Consulting Psychology 21, 95-103.

Roth, P.L., Switzer, F.S., Switzer, D., 1999. Missing data in multi-item scales: A Monte Carlo Analysis of missing data techniques. Organizational Research Methods 2 (3), 211-232.

Schmalenberg, C., Kramer, M., 2008. Essentials of a productive nurse work environment. Nursing Research 57 (1), 2-13.

Sellin, N., 1995. Partial least squares modeling in research on educational achievement. In: Bos, W., Lehmann, R.H. (Eds.), Reflections on Educational Achievement: Papers in Honour of T. Neville Postlethwaite. Waxmann Munster, New York, pp. 256-267.

Shattell, M.M., Starr, S.S., Thomas, S.P., 2007. 'Take my hand, help me out': Mental health service recipients' experience of the therapeutic relationship. International Journal of Mental Health Nursing 16 (4), 274-284.

Shaw, S., Cartwright, A.K.J., Spratley, T., Harwin, J., 1978. Responding to drinking problems. Croom Helm, London.

Shullanberger, G., 2000. Nurse staffing decisions: an integrated review of the literature. Nursing Economic\$18 (3), 124-148.

SPSS Inc., 2007. SPSS for Windows. SPSS Inc., Chicago.

Stockmann, C., 2005. A literature review of the progress of the psychiatric nurse-patient relationship as described by Peplau. Issues in Mental Health Nursing 26, 911-919.

Tenenhaus, M., Esposito-Vinzi, V., Chaetlin, Y.-M., Lauro, C., 2005. PLS path modeling. Computational Statistics and Data Analysis 48, 159-205.

Temme, D., Kreis, H., \& Hildebrandt, L., 2006. PLS Path Modeling - A Software Review. (2006-084). Humbolt Universitat zu Berlin, Berlin.

Tervo-Heikkinen, T., Partanen, P., Aalto, P., Vehviläinen-Julkunen, K., 2008. Nurses' work environment and nursing outcomes: A survey study among Finnish university hospital registered nurses. International Journal of Nursing Practice 14 (5), 357-365.

Tourangeau, A.E., Doran, D.M., McGillis-Hall, L., O'Brien-Pallas, L.L., Pringle, D., Tu, J.V., Cranley, L.A., 2007. Impact of hospital nursing care on 30-day mortality for acute medical patients. Journal of Advanced Nursing 57 (1), 32-44.

Van Bogaert, P., Clarke, S.P., Vermeyen, K., Meulemans, H., Van de Heyning, P., 2009. Practice environments and their associations with nurse-reported outcomes in Belgian hospitals: Development and preliminary validation of a Dutch adaptation of the Revised Nursing Work Index. International Journal of Nursing Studies 46 (1), 55-65. 
Van den Heede, K., Clarke, S.P., Sermeus, W., Vleugels, A., Aiken, L.H., 2007. International experts' perspectives on the state of the nurse staffing and patient outcomes literature. Journal of Nursing Scholarship 39 (4), 290-297.

Warshawsky, N.E., Havens, D., 2011. Global use of the Practice Environment Scale of the Nursing Work Index. Nursing Research 60 (1), 17-31.

Werts, C.E., Linn, R.L., Joreskog, K.G., 1974. Intraclass reliability estimates: testing structural assumptions. Educational and Psychological Measurement 34, 25-33.

White, E., Roche, M.A., 2006. A selective review of mental health nursing in New South Wales, Australia, in relation to clinical supervision. International Journal of Mental Health Nursing 15 (3), 209-219.

Wierdsma, A., Mulder, C., de Vries, S., Sytema, S., 2009. Reconstructing continuity of care in mental health services: A multilevel conceptual framework. Journal of Health Services Research \& Policy 14 (1), 52-57.

Wong, Y.K., 2006. Modern Software Review: Techniques and Technologies. IRM Press, Hershey, USA. 